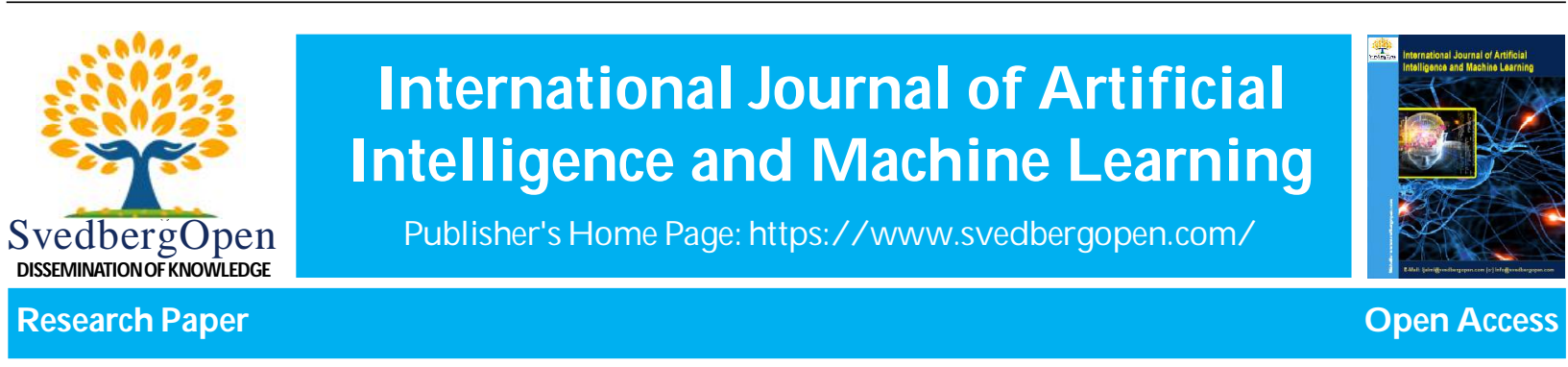

\title{
Artificial Intelligence and conscious brain waves
}

\author{
Gholam Soltani ${ }^{1^{*}}$ \\ ${ }^{1}$ Independent, Tehran, Iran. E-mail: soltani_gh@yahoo.com
}

\section{Article Info}

Volume 1, Issue 1, July 2021

Received : 18 February 2021

Accepted : 17 June 2021

Published : 05 July 2021

doi: 10.51483/IJAIML.1.1.2021.11-17

\begin{abstract}
The human brain emits waves that we do not feel. The waves emanating from the brain are conscious and aware. The human brain is made up of a large number of nerve cells called neurons. The brain sends various messages to different parts of the body and receives messages from them through neurons. Human brain waves can also communicate directly with Artificial Intelligence. Artificial intelligence is concerned with intelligent behavior in artifacts and has three common characteristics with human being: learning, problem-solving and decision-making. The direct connection between human brain waves and artificial intelligence is a challengeable issue, because it has lots of advantages and disadvantages. One of the most challengeable issues is reading the human mind by artificial intelligence, that is, the privacy of people will be in danger. Another issue is that governments can control their people according to their own will, not the will of the people. On the other hand, direct connection between human brain waves and artificial intelligence has lots of advantages, among them, solving the problem of dumb people, resolving family disputes, creating peace and intimacy between people, increasing the power of memory and strengthening the immune system can be mentioned. As this technique will appear soon, it is necessary to inform people of it and codify its specific rules and regulations in order to avoid misuse it.
\end{abstract}

Keywords: Artificial Intelligence, Conscious brain Waves, Mind reading

(C) 2021 Gholam Soltani. This is an open access article under the CC BY license (https: //creativecommons.org/licenses/by/4.0/), which permits unrestricted use, distribution, and reproduction in any medium, provided you give appropriate credit to the original author(s) and the source, provide a link to the Creative Commons license, and indicate if changes were made.

\section{Introduction}

The human brain emits waves that we do not feel. The waves emanating from the brain are conscious and aware. Brain waves have such an incredible power that can do anything. Human brain waves are able to pass through all objects without any deviation or problem and travel at super speed to infinitely far distances. ${ }^{1}$ If the human brain waves are strong enough, they can stop an airplane in the sky and even interfere with human happiness and misery.

* Corresponding author: Gholam Soltani, Independent, Tehran, Iran. E-mail: soltani_gh@yahoo.com

${ }^{1}$ Kabook. (1993). Second World and Hypnosis, p. 30. Kabook Publication. Tehran. Iran.

2789-2557/@ 2021. Gholam Soltani. This is an open access article distributed under the Creative Commons Attribution License, which permits unrestricted use, distribution, and reproduction in any medium, provided the original work is properly cited. 
The human brain is made up of a large number of nerve cells called neurons. Neurons are present throughout the body. Communication between different parts of the brain and between the brain and other parts of the body is done through these nerve cells and by nerve messages. In fact, the brain sends various messages to different parts of the body and receives messages from them through these nerve cells. The nature of this neural message is in the form of an electric current inside a cell and in the form of chemical transitions between two cells. The electrical activity of neurons at the surface of the skull causes the formation of the electrical activity of the brain called brain waves ${ }^{2}$. Human brain waves can also communicate directly with Artificial Intelligence (AI).

AI, broadly (and somewhat circularly) defined, is concerned with intelligent behavior in artifacts. Intelligent behavior, in turn, involves perception, reasoning, learning, communicating and acting in complex environments. ${ }^{3}$ Therefore, "learning, problem-solving and decision-making are three common characteristics of human and artificial intelligence."4 Today, artificial intelligence has reached such a level of capability and sophistication that can even invent without human intervention. Many examples of AI-generated inventions have been patented. ${ }^{5}$

This paper seeks to show what will happen if artificial intelligence can communicate directly with the conscious brain waves of the human? What would be the privacy of individuals if artificial intelligence could read human minds? Will artificial intelligence be able to solve the problem of dumb people and turn their thoughts into speech by communicating directly with their conscious brain waves? And several other important questions that I will answer scientifically for the first time in the world.

\section{Conscious brain waves}

\subsection{Nerve cell and its structure}

The nervous system is unique in the vast complexity of thought processes and control actions it can perform. Each minute it receives literally millions of bits of information from the different sensory nerves and sensory organs and then integrates all these to determine responses to be made by the body. The central nervous system contains more than 100 billion neurons. ${ }^{6}$

A neuron, or nerve cell, is an electrically excitable cell that communicates with other cells via specialized connections called synapses. It is the main component of nervous tissue in all animals except sponges and placozoa. Plants and

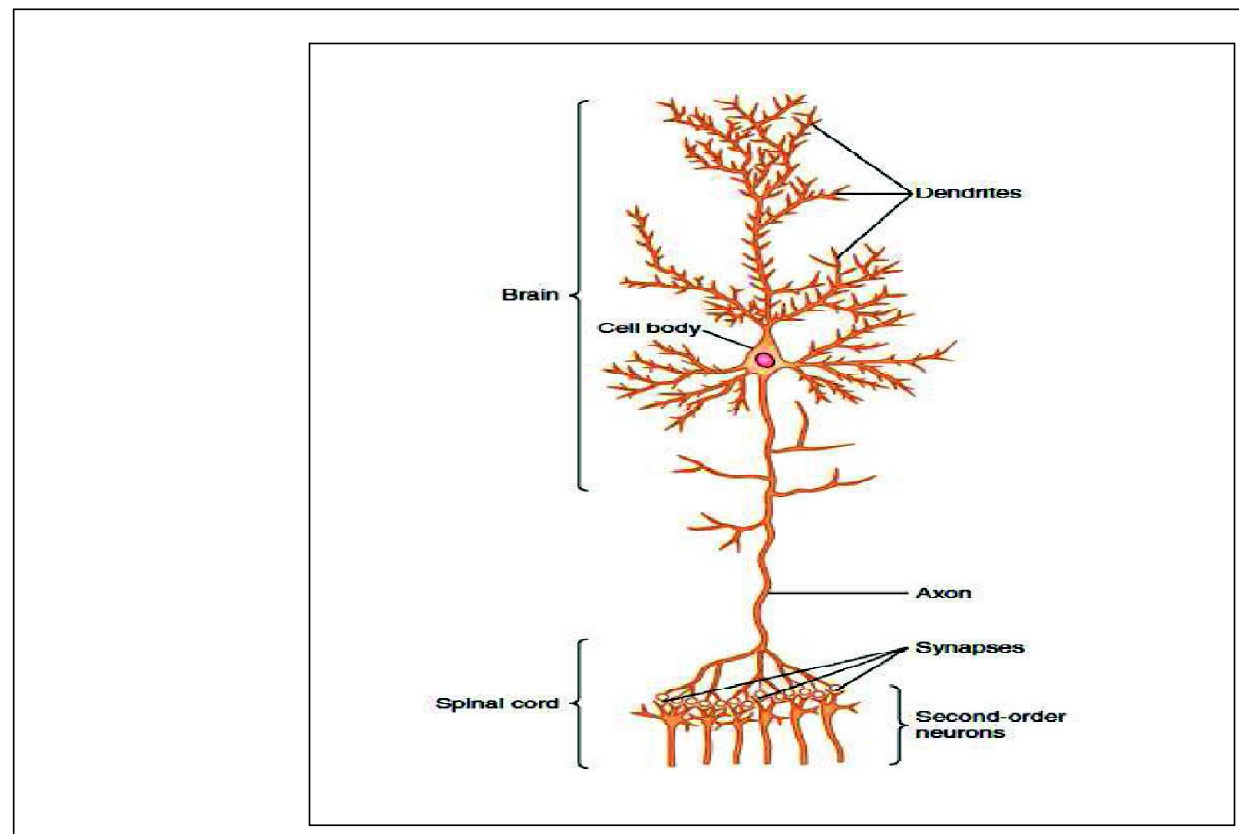

Figure 1: Nerve cell's structure

\footnotetext{
${ }^{2}$ http://teh-jounoob.pnu.ac.ir/portal/file/?1353294/QEEG

${ }^{3}$ Nilsson, N.J. (1998). Artificial Intelligence: A New Synthesis, p. 1, Morgan Kaufmann. San Francisco. CA. USA.

${ }^{4}$ WALTL, Bernhard., and VOGL, Roland. (2018). Explainable Artificial Intelligence - The New Frontier in Legal Informatics. p. 1. in: Jusletter IT, February 22, 2018.

${ }^{5}$ One example is Dr. Thaler's Creativity Machine's Patent named "Neural Network Based Prototyping System and Method" (U.S. Patent No. $5,852,815)$.

${ }^{6}$ John, E. Hall., and Arthur, C. Guyton. (2016). Guyton and Hall Textbook of Medical Physiology, p. 577. 13 ${ }^{\text {th }}$ edition. Elsevier. USA.
} 
fungi do not have nerve cells. ${ }^{7}$ Neurons vary in size, shape, and structure depending on their role and location. However, nearly all neurons have three essential parts: a cell body, an axon, and dendrites. ${ }^{8}$ (see Figure 1$)^{9}$

\subsection{Cell body}

Like other cells, each neuron has a cell body (or soma) that contains a nucleus, smooth and rough endoplasmic reticulum, Golgi apparatus, mitochondria, and other cellular components. ${ }^{10}$ The soma, or cell body, is where the signals from the dendrites are joined and passed on. The soma and the nucleus do not play an active role in the transmission of the neural signal. Instead, these two structures serve to maintain the cell and keep the neuron functional. ${ }^{11}$

\subsection{Axon}

An axon is a long, slender projection of a nerve cell, or neuron that typically conducts electrical impulses known as action potentials away from the nerve cell body. The function of the axon is to transmit information to different neurons, muscles, and glands. ${ }^{12}$

\subsection{Dendrites}

Dendrites are fibrous roots that branch out from the cell body. Like antennae, dendrites receive and process signals from the axons of other neurons ${ }^{13}$ and transmit electrical stimulation to the soma. Dendrites are also covered with synapses. ${ }^{14}$ Neurons can have more than one set of dendrites, known as dendritic trees. ${ }^{15}$

\subsection{Substance of Brain Waves}

Humans have five basic senses: touch, sight, hearing, smell and taste. The sensing organs associated with each sense send information to the brain to help us understand and perceive the world around us. ${ }^{16}$ The eyes translate light into image signals for the brain to process, the ear uses bones and fluid to transform sound waves into sound signals, specialized receptors in the skin send touch signals to the brain, chemicals in the air, through the nose, stimulate signals the brain interprets as smells, and the tongue is the principal organ of gustation. ${ }^{17}$ Sound energy by the ears, light energy by the eyes, chemical energy by the nose and tongue, and heat energy by the skin are converted into electrical energy and sent to the brain, where they are recorded, and emitted as electromagnetic waves from the brain. ${ }^{18}$

Given the above descriptions of the five senses, it must be accepted that the ears, eyes, nose, tongue, and skin of the body function as receivers and transmitters, that is, they receive reports from their surroundings and send them to the brain. "Like a wireless, the brain converts electrical energy within its range into electromagnetic energy and emits it into space. At the same time, it receives electromagnetic waves or electromagnetic energy from space and converts them into electrical energy. This round-trip sequence of energies is called the electromagnetic field of the brain." 19

\section{Types of brain waves}

At the root of all our thoughts, emotions and behaviors is the communication between neurons within our brains. Brain waves are produced by synchronized electrical pulses from masses of neurons communicating with each other. ${ }^{20}$ Brain waves are oscillating electrical voltages in the brain measuring just a few millionths of a volt. ${ }^{21}$ There are five different types of brain waves, ranging from low to high frequency:

Delta brain waves are the slowest brain waves. They are generated in deep meditation and dreamless sleep. Healing and regeneration occur when the brain is in this state.

\footnotetext{
${ }^{7}$ https://en.wikipedia.org/wiki/Neuron

${ }^{8}$ https://www.healthline.com/health/neurons\#parts

9 John, E. Hall., and Arthur, C. Guyton. (2016). op. cit., p. 578.

${ }^{10} \mathrm{https}$ //courses.lumenlearning.com/boundless-psychology/chapter/neurons/

${ }^{11} \mathrm{https}$ ///www.verywellmind.com/structure-of-a-neuron-2794896\#citation-2

12 https://en.wikipedia.org/wiki/Axon

${ }^{13} \mathrm{https} / / / \mathrm{www} \cdot h$ althline.com/health/neurons\#parts

${ }^{14}$ https://www.verywellmind.com/structure-of-a-neuron-2794896

15 https://www.healthline.com/health/neurons\#parts

${ }^{16} \mathrm{https}: / /$ www.livescience.com/60752-human-senses.html

${ }^{17} \mathrm{https}: / /$ www.visiblebody.com/learn/nervous/five-senses

${ }^{18}$ Arbabi, GholamReza. (1996). The wonders of the sixth sense or the radio-television waves of the human brain, Arbabi Cultural Group Publication, Tehran, Iran, p.18.

${ }^{19}$ Ibid., p.23.

${ }^{20} \mathrm{https}$ ///brainworksneurotherapy.com/what-are-brainwaves

${ }^{21} \mathrm{https}$ ://www.sciencedirect.com/topics/agricultural-and-biological-sciences/brain-waves
} 
Theta waves also occur in sleep and during relaxation. They are indicative of an inner focus, dreams and vivid imagery occur in this state.

Alpha waves occur during quiet, thoughtful times. Alpha waves indicate that the brain is in resting state.

Beta waves are the most common pattern in the normal waking state. They occur when one is alert and focused on problem solving.

Gamma brain waves are the fastest and are associated with higher levels of consciousness. ${ }^{22}$

For the first time in the world, Dr. Hans Berger, a German psychiatrist, invented a device in 1924 that could record brain waves and called it an electroencephalogram, or EEG. ${ }^{23}$ Since his discovery, EEGs have been used to provide useful information about one's mental state and functioning, as they can lead to the diagnosis of epilepsy, sleep conditions, Alzheimer's, and other issues related to brain functioning. ${ }^{24}$ Today, more modern systems have replaced the electroencephalogram, which are able to receive brain waves and record the type of waves without direct communication. ${ }^{25}$

\section{Brain as a transmitter and receiver}

The brain is an electromagnetic transmitter and receiver, ${ }^{26}$ carrying the vibrations of your thoughts and feelings out into the world. So here you are, a human being who carries around this powerful instrument for receiving and transmitting vibrations of energy. And those vibrations of energy co-create the reality you live in, rearranging the atoms of your world in response to the frequency you are sending out. ${ }^{27}$

The human brain, like a radio or television transmitter and receiver, is always active, emitting what it contains as electromagnetic waves or receiving waves at the same wavelength from the outside. The difference is that the transmitters or receivers of television deal only with light (image) and sound, while the transmitter and receiver of our brain, in addition to light and sound, deals with various tastes, smell, and feelings, and manages internal and external affairs of the body as well. ${ }^{28}$

To clarify the matter, I give two examples. The first one is that while you are out of home, suddenly it comes to your mind that you should take two bottles of milk. No one has told you it before. When you get home, your spouse says: "I wanted to call you to get two bottles of milk, but suddenly the baby cried and I could not call you again." You say: "I got two bottles of milk myself." Your spouse says: "Oh my God!" Here your spouse sent you the brain wave carrying the message of buying milk and your brain received it. This situation is called telepathy ${ }^{29}$ or remote brain-to-brain communication.

The second situation is that someone's face is itchy. This itching is reported to the brain through the nerves and accordingly, electromagnetic waves are emitted from the brain. If a device can receive these brain waves, which are in proportion to the itching of the face, and mount them on the wavelength of a particular person and send them to him/her, his or her face begins to itch for no reason.

\section{Brain waves' consciousness}

The waves emanating from the brain are conscious and aware. Brain waves have such an incredible power that can do anything. To illustrate, I give some examples. Dr. Joseph Murphy, in his book, The Power of Your Subconscious Mind, says: A few months ago, I received a letter from a woman named, Ruth A. who had attended my lectures. She wrote: I am seventy-five years old, a widow with a grown family. I was living alone, on a small pension and Social Security. My life seemed barren, hopeless. Then I remembered your lecture about the powers of the subconscious mind. You said that ideas could be conveyed to the subconscious mind by repetition, faith, and expectancy. Could it be true? I decided to try. I had nothing to lose. I began to repeat frequently, with all the feeling I could muster, "I am wanted. I am loved. I am happily married to a kind, loving, and spiritual-minded man. I am secure and fulfilled." I kept on doing this many times a day for about two weeks. One day at the corner drugstore, I was introduced to a retired pharmacist. I found him to be kind, understanding, and very religious. He was a perfect answer to my prayer. Within a week he proposed to me. Now

22 https://www.goodtherapy.org/blog/psychpedia/brain-waves

${ }^{23}$ Arbabi, GholamReza. (1996). op. cit., p. 52.

${ }^{24}$ https://www.goodtherapy.org/blog/psychpedia/brain-waves

${ }^{25}$ Arbabi, GholamReza. (1996). op. cit., p. 52.

${ }^{26} \mathrm{https}$ ://www.quora.com/Is-the-brain-a-receiver-a-transmitter-both-or-neither

${ }^{27}$ https://thriveglobal.com/stories/understanding-our-natural-ability-to-receive-and-transmit-energy/

${ }_{28}$ Arbabi, GholamReza. (1996). op. cit., p. 77.

${ }^{29}$ Telepathy - the power of sending information from one mind to another without the aid of normal senses-Taylor. John, Superminds. The Viking Press. New York. USA. 1975, p. 8. 
we are on our honeymoon in Europe. I know that the intelligence within my subconscious mind brought both of us together in divine order. ${ }^{30}$

As we have already learned, the thought stems from the brain. When you think, your brain emits waves according to the nature of your thought. These waves hold your thought and act as your thought desires. Your brain waves search everywhere to find your subject. "Ruth discovered that the treasure house was within her. Her deeper mind, full of wisdom and intelligence, brought her and her new husband together in divine order." 31

The second example is the Robert Pavlita's generators which work by the conscious brain waves. "Pavlita stood six feet away and did no more than stare hard at his generator. After a while the blade on the fan began to slow down, as though the current had been cut off; then it stopped altogether and began to rotate in the opposite direction. It has nothing to do with static electricity, air, current, temperature changes, or magnetism, but it works only by the brain waves." 32

As you read in the experiment above, the electric fan first stops and then starts to rotate in the opposite direction. That is, the electric fan rotates in the same direction as the brain wants. In other words, brain waves are the consciousness of the organism.

On the evening of Friday, November 23, 1973, British television viewers were surprised and baffled by the incredible sight of a fork collapsing under the influence of Uri Geller, an entertainer from Israel. Not only did he cause the fork to break after a minute's gentle stroking, but he was able, without touching it, to cause the bending of another one lying nearby on the table. He followed this up by restarting a stopped watch, bending the second hand inside the watch glass, and capped his performance by correctly guessing the details of a drawing sealed in two envelopes. ${ }^{33}$

These objects were all bent out of their natural shape by the power of the mind alone-a process called psychokinesis. ${ }^{34}$ The spring was held very briefly between the subject's forefinger and thumb. A girl of thirteen bent the aluminum comb and brass strip and also broke the spoon by stroking them gently. The spoon was bent without touching by a boy of sixteen, and a boy of thirteen, similarly fashioned the paper-clip dog. That Uri Geller and an increasing number of others, many of them children, can bend cutlery, keys, and other metal objects merely by rubbing them or even by concentrating on them is no longer in dispute. ${ }^{35}$

The conclusions that can be drawn from the above are as follows:

"Firstly, when brain waves are able to affect inanimate and solid metal objects, they can be more effective on living beings, i.e., humans and animals.

Secondly, when the brain waves of a human are able to communicate with other human brain waves, then humans can be forced to do anything remotely by sending brain waves to them.

Thirdly, the root and cause of black and white magic are revealed, meaning that humans can be sick, killed, loved, become insane, and so on." 36

\section{Mind reading}

Mind reading means: "The ability to discern the thoughts of others without the normal means of communication, especially by means of a preternatural power; an act or the practice of so discerning the thoughts of another." ${ }^{37}$ Thus, mind reader means: "a person who knows what somebody else is thinking without being told." 38

When thinking, exclusive electrical exchanges take place in the brain, which move in specific pulses in closed neural circuits. To understand this mechanism, it is better to reduce the volume of a radio that works at a certain wavelength to zero. The interaction that takes place in the radio is what that takes place exactly in the brain when thinking. Now if you increase the volume of the radio, you will hear its sound. So talking means thinking aloud (radio speaks and broadcasts). To be silent and to think means to speak without sound (a radio that works but we have reduced the volume to zero).$^{39}$

\footnotetext{
${ }^{30}$ Murphy, Joseph. (2019). The Power of Your Subconscious Mind. pp. 19-20. St. Martin's Essentials. USA.

31 Ibid., p. 20.

32 Watson, Lyall. (1973). Super Nature, p. 187. Anchor Press. USA.

${ }^{33}$ Taylor, John. (1975). Superminds, p. 8. The Viking Press. New York. USA.

${ }^{34}$ The act of moving an object by using the power of the mind. https://www.oxfordlearnersdictionaries.com/definition/english psychokinesis?q=psychokinesis

35 Taylor, John. (1975). op. cit., p. 2.

${ }^{36}$ Kabook. (1993). op. cit., p. 35.

37 https://www.dictionary.com/browse/mind-reading

$38 \mathrm{https}$ ///www.oxfordlearnersdictionaries.com/definition/english/mind-reader? $\mathrm{q}=$ mind+reader

39 Arbabi, GholamReza. (1996). op. cit., p. 144.
} 
The source of thought is the brain. When you are thinking, the brain emits electromagnetic waves that have a specific wavelength and carry the message contained in your mind. If a device that works with artificial intelligence can receive these waves directly and convert them into speech, text or picture, then your mind has been read by this device. I will explain in detail how AI is directly connected to the human brain in my next paper.

\section{Advantages and disadvantages of direct connection between artificial intelligence and human conscious brain waves}

As mentioned above, every wave that emits from the human brain carries a message. This message may or may not be voiced. That is, a person can express his/her message by talking, or just think about it. The latter is especially true for dumb people, who do not have the ability to speak to convey their brain message aloud. If artificial intelligence can read the brain waves of these people, then their thoughts will be turned into speech and the problem of dumb people will be solved. On the other hand, artificial intelligence can be very useful for blind people, because if every blind person has an artificial intelligence device with them, it can help them along the way and explain the world ahead and save them from many dangers. After all, by direct connection of artificial intelligence with the conscious brain waves of animals, these creatures will also have their own language, because their thoughts will be turned into speech, text or picture.

We know that every wave emitted from the human brain has a certain wavelength. Each person has their own wavelength. That is, there are as many wavelengths as the number of people on the planet. Now, what if artificial intelligence could communicate directly with the human brains and store the wavelengths of different people in its memory? It is like an archive center that contains the wavelengths of people. These wavelengths act as the identity cards of individuals and contain all the information about each person. This means that whenever someone wants to think, the thought is released through electromagnetic waves into space and enters the memory of a computer with artificial intelligence. In this case, no one has privacy anymore. This means that artificial intelligence will have accurate and confidential information of all people around the world.

Since each person has their own wavelength, artificial intelligence can put any kind of emotion on the wavelength of people and send it to their brains. Emotions such as fear, cry, sneeze, cough, laugh and so on. Suppose 20 people are sitting in a room. Here are twenty types of wavelengths. Artificial Intelligence knows what wavelength each person has. In this case, it can make a different feeling for each of them to ride on their wavelength, and each of these people laughs, cries, coughs and sneezes involuntarily, because these waves cannot be resisted. Or put one feeling on the wavelength of all people and all of them at the same time hit their heads and faces. This is a small example of controlling people. With this technique, all human beings can be easily controlled and any calamity can befall them. On the other hand, codes of happiness, treatment of diseases, resolving family disputes, increasing memory power and strengthening the immune system can also be mounted on the wavelength of people and sent to their brains. Even artificial intelligence can hypnotize people remotely.

\section{Conclusion}

Through the direct connection of artificial intelligence with the conscious brain waves of the human, in addition to its many benefits, there is no longer privacy for individuals. All the secrets of humans are in the hands of artificial intelligence and those who work with these computers. On the other hand, human beings can be controlled as AI wishes and forced to do anything. Obviously, governments will use artificial intelligence to run society and their work will be very easy. In the meantime, people who work with artificial intelligence devices must be very confidential and honest who both keep people's secrets and do not harm people. Given the rapid advancement of science, it is obvious that in the near future, artificial intelligence will communicate directly with the conscious brain waves of the human and will be exploited as governments wish. In the meantime, before using this technique, it is necessary to inform the public of it and codify specific rules for it, because with this technique, the world can be turned into both the hell and the ideal paradise.

\section{References}

\section{Publications}

Arbabi, GholamReza. (1996). The wonders of the sixth sense or the radio-television waves of the human brain, Arbabi Cultural Group Publication. Tehran. Iran.

John, E. Hall., and Arthur, C. Guyton. (2016). Guyton and Hall Textbook of Medical Physiology, Thirteenth edition, Elsevier, USA. 
Kabook. (1993). Second World and Hypnosis. Kabook Publication. Tehran, Iran.

Murphy, Joseph. (2019). The power of your subconscious mind. St. Martin’s Essentials. USA.

Nilsson, N.J. (1998). Artificial Intelligence: A new synthesis. Morgan Kaufmann. San Francisco. CA. USA.

Taylor, John. (1975). Superminds. The Viking Press. New York. USA.

WALTL, Bernhard., and VOGL, Roland. (2018). Explainable artificial intelligence - The new frontier in legal informatics, in: Jusletter IT. February 22, 2018.

Watson, Lyall. (1973). Super Nature. Anchor Press. USA.

\section{Websites}

http://teh-jounoob.pnu.ac.ir/portal/file/?1353294/QEEG

https://brainworksneurotherapy.com/what-are-brainwaves

https://courses.lumenlearning.com/boundless-psychology/chapter/neurons/

https://en.wikipedia.org/wiki/Axon

https://en.wikipedia.org/wiki/Neuron

https://thriveglobal.com/stories/understanding-our-natural-ability-to-receive-and-transmit-energy/

https://www.dictionary.com/browse/mind-reading

https://www.goodtherapy.org/blog/psychpedia/brain-waves

https://www.healthline.com/health/neurons\#parts

https://www.livescience.com/60752-human-senses.html

https://www.oxfordlearnersdictionaries.com/definition/english/mind-reader?q=mind+reader

https://www.oxfordlearnersdictionaries.com/definition/english/psychokinesis?q=psychokinesis

https://www.quora.com/Is-the-brain-a-receiver-a-transmitter-both-or-neither

https://www.sciencedirect.com/topics/agricultural-and-biological-sciences/brain-waves

https://www.verywellmind.com/structure-of-a-neuron-2794896

https://www. visiblebody.com/learn/nervous/five-senses

Cite this article as: Gholam Soltani. (2021). Artificial Intelligenceand conscious brain waves. Internati onal Journal of Artificial Intelligenceand M achineLearning, 1(1), 11-17. doi: 10.51483/ IJAIML.1.1.2021.11-17. 